\title{
Study on Variations of Isotopes and Phosphate of Soil Water in Water Infiltration Process
}

\author{
SUN Xiao Xu \\ School of Environmental Engineering, Nanjing Institute of Technology, Nanjing 211167, China \\ email : hjsunxiaoxu@njit.edu.cn
}

Keywords: hydrogen-oxygen, phosphate, soil particles, migration law

\begin{abstract}
In this paper, in order to study on the influences of hydrogen-oxygen isotope values and phosphate content of soil water, rainfall and sewage infiltration process were simulated through the soil column experiment. Soil water samples were collected in situ, and the gravity flow samples were also collected. Through the analysis of hydrogen-oxygen isotope values and phosphate content, the conclusion is that in the rainfall infiltration process of dry soil, the light water molecules are first adsorbed by soil particles, the first gravity flow water sample had the most positive isotope values. Soil particles had the purification effect to the phosphate in wastewater, and the purification effect under acidic conditions was better than alkaline conditions, phosphate was more easily rinsed out under alkaline conditions.
\end{abstract}

\section{Introduction}

Vadose zone is a zone in which the meteoric water, surface water and groundwater are interconnected, and has water exchanges with each other. The vadose zone is also a complicated system in which geotechnical particle, water and air exist at the same time. The migration of water and transformation of substance lead very important roles in the formation and evolution of groundwater.

The migration of water in vadose zone is a very complicated physical and chemical procedure, which is controlled and limited by multiple stress and varied energy. With the fast development of science and technology, more and more new methods are used to research vadose zone water ${ }^{[1]}$. Stable isotopes of hydrogen and oxygen (D and ${ }^{18} \mathrm{O}$ ), as a natural tracer, move with water flow, which represents the characteristics of water migration. Many scholars use stable isotopes in soil water to trace transportation process of water in the soil and provide some migration information of water in vadose zone ${ }^{[2-6]}$. However, hydrogen and oxygen isotopes of soil water in vadose zone are influenced by a series of procedures of rainfall infiltration, soil evaporation and phreatic evaporation. Soil water evaporation and rainfall infiltration have close relationships with properties of soil particles ${ }^{[7-8]}$. Sun xiaoxu et al. ${ }^{[9]}$ studied variation of hydrogen and oxygen isotopes in process of soil water evaporation and rainfall infiltration by the inside simulation experiment. The migration of pollutants in the soil is also a very complicated procedure, which combines physical, chemical and biotic action. Domestic and international scholars did much research on the migration of pollutants in the soil, especially the migration of pollutants in vadose zone in the condition of rainfall. In numerical simulation, Grifoll and Cohen ${ }^{[10]}$ set up the one-dimensional pollutants' equation in vadose zone, studied the migration of pollutants in the condition of rainfall and evaporation using implicit finite difference method. Marshall et al. ${ }^{[1]}$ studied the variation of 
pollutant concentration in rainfall infiltration stochastic by setting up migration model of one-dimensional conservative pollutants. Li hong et al. ${ }^{[12]}$ taking organic pollutants (benzene) as research object, simulated vertical one-dimensional migration procedure of organic pollutants in the soil seepage zone. Zuo zibo et al. ${ }^{[13]}$ used finite element numerical analysis to simulate procedure of pollutant migration in the saturated soil and unsaturated soil in conditions of open-air, continuous rainfall and discontinuous rainfall. Lin fei et al. ${ }^{[14]}$ studied chloride's migration trend in saturated silt in the condition of different kinds of rainfall based on numerical model of three dimensional solute transport of groundwater in FEMWATER saturated soil and unsaturated soil. In experiment simulation, Wang chao ${ }^{[15]}$ used soil column physical model experimental device to study migration rule of nitrogen pollutant in the soil. Wang yanan et al. ${ }^{[16]}$ studied the moving-transiting theory of phosphorus in the soil on the basis of pillar experiment. Ji xueyan et al. ${ }^{[17]}$ studied the migration of petroleum pollutants in the soil through soil column experiments by layers. Xian chunyan et al. ${ }^{[18]}$ simulated the experiment on migration process of soil water interface of organo-chlorine pesticides existing in the rainfall. The research demonstrates that organo-chlorine pesticides of the output of surface runoff is higher than that of soil seepage fluid, and the organo-chlorine pesticides of the output in soil runoff took on a trend from decline to rise.

On the movement of vadose zone water, owe to a series of complicated procedures of infiltration, desorption and chemical actions, soil particle leads a critical role in migration rule of different elements in the water. Hydrogen and oxygen has finger print effect. $\mathrm{PO}_{4}-\mathrm{P}$ is one kind of earliest discovered crop-required nutrient element, which is also one kind of elements most studied by soil workers. In this paper, experiment simulation of rainfall infiltration on vadose zone was carried out. There was the study on migration laws of hydrogen, oxygen and $\mathrm{PO}_{4}-\mathrm{P}$ in the vadose zone, which can give a base for future researches.

\section{Test design and measurement}

\section{Materials}

In this experiment, plexiglass columns of $\Phi 104 \mathrm{~mm} \times 1100 \mathrm{~mm}$ were experimental containers. The bottom of the column is porous plate to make water flow smoothly. To ensure that the rainfall infiltration in the first part of the first infiltration flow out of the column, we put a circular inclined plate under the column and water flows along the inclined plate smoothly. The schematic diagram of the experimental apparatus is shown in Figure 1 and the diagram of the experimental apparatus is shown in Figure 2.

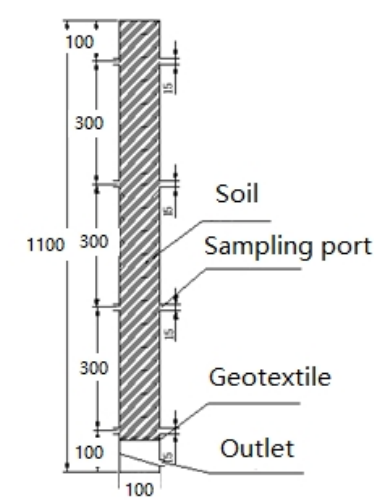

Fig 1 Schematic diagram of the experiment

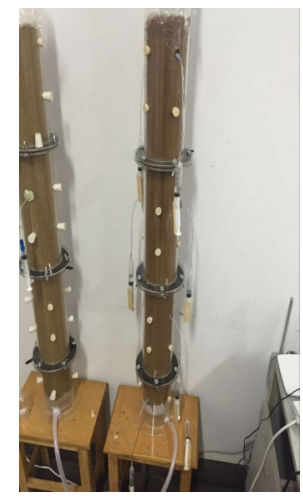

Fig 2 Diagram of the experimental equipment

Soil samples for test were collected from green belts in NJIT. In the definite sampling point, firstly, clean up surface weeds, rocks, worn shell and roots, the sampling depth was 10-20cm from surface layer. After naturally air dry, grate, screening by $2 \mathrm{~mm}$ sieve, the soil was mixed bag aside. 
According to $<<$ Soil Classification Criterion $>>($ GBJ145-90 ), the type of soil sample for test was silty loam.

\section{Experimental design and sample collection}

The sampling depth was $10 \mathrm{~cm}, 40 \mathrm{~cm}, 70 \mathrm{~cm}$ and $100 \mathrm{~cm}$ from the surface of column. Soil column was filled uniformly with pre treated soil samples and plug in sample hole before water infiltration. Soil solution sampler inserted the soil column through sample holes, collecting soil water samples in situ. The type of sampler is Rhizon-SMS 19.21.01. One side of the sampler was inserted to the soil. The other side was connected with a syringe to extract soil water artificially.

(1) Research on migration of hydrogen and oxygen isotopes

In this experiment, tap water was used to simulate rainfall. In the first process of rainfall, the water permeated to the bottom of soil column but it can't outflow. By the total mass of filling, we can obtain $2600 \mathrm{ml}$ of infiltration water in the first process of rainfall. Ponding infiltration was used because the permeability coefficient of silty loam was very small(about 10-5 10-6cm/s). In the first process of rainfall, the thickness of ponding water basically keep in $3 \mathrm{~cm}$ until $2500 \mathrm{ml}$ of rainfall permeated totally. In order to have a uniform distribution of water in the soil column, the column was stand for 48 hours. Soil water was sampled in the four horizon which respectively was $10 \mathrm{~cm}$, $40 \mathrm{~cm}, 70 \mathrm{~cm}$ and $100 \mathrm{~cm}$. Each sample is obtained in two sampling aperture at the same time in order to maintain the uniformity of water. The sample numbers were respectively 1a,1b,1c and $1 \mathrm{~d}$. The sampler of soil water solution was keeping in its place for later sampling. The second rainfall of $500 \mathrm{ml}$ infiltrated, there were water outflow from the bottom of soil column. We collected 7 samples of gravity outflow water successively for later experiment. When there were no water outflow from the bottom of soil column, we collected 4 samples of soil water in situ. The sample numbers were $2 \mathrm{a}, 2 \mathrm{~b}, 2 \mathrm{c}$ and $2 \mathrm{~d}$.

(2) The research of carbonate's transferring disciplinarian

Phosphorus in wastewater was prepared with $\mathrm{NaH}_{2} \mathrm{PO}_{4} \cdot 2 \mathrm{H}_{2} \mathrm{O}$ and deionized water. The initial concentration of phosphorus is $129 \mathrm{mg} / \mathrm{L}$. Considering the impact of $\mathrm{pH}$ on transferring disciplinarian of phosphorus in the soil, the wastewater is divided into two parts uniformly. One part of $\mathrm{pH}$ is about 3 and the other one is about 11.

Phosphorus in wastewater infiltrated into soil profile. In the first process of infiltration, the total infiltration amount was $2750 \mathrm{ml}$. The water had permeated to the bottom of soil column and there were no gravity outflow water. After standing for $48 \mathrm{~h}$, soil water was sampled in the four horizon which respectively is $10 \mathrm{~cm}, 40 \mathrm{~cm}, 70 \mathrm{~cm}$ and $100 \mathrm{~cm}$. Every horizon's sample was obtained in two sampling aperture. The sample numbers were $1 \mathrm{~A}, 1 \mathrm{~B}, 1 \mathrm{C}$ and $1 \mathrm{D}$. In order to simulate the process of rainfall leaching the polluted soil, tap water of $2000 \mathrm{ml}$ permeated the soil profile which had been polluted. There were water outflowing from the bottom of equipment. When there were no water outflowing from the bottom, we collected soil water in the four horizons $(10 \mathrm{~cm} 、 40 \mathrm{~cm}$,

$70 \mathrm{~cm} 、 100 \mathrm{~cm})$. The samples numbers were respectively $2 \mathrm{~A}, 2 \mathrm{~B}, 2 \mathrm{C}, 2 \mathrm{D}$ for later experiment.

\section{The testing and analytical method of sample}

Stable isotope analysis was conducted at the State Key Laboratory of Hydrology, Water Resources and Hydraulic Engineering, Hohai University. The hydrogen and oxygen isotopes were reported in delta $(\delta)$ notation as permil $(\% o$ ) differences relative to the V-SMOW ( Vienna standard mean ocean water ) international standard. ${ }^{2} \mathrm{H} /{ }^{1} \mathrm{H}$ and ${ }^{18} \mathrm{O} /{ }^{16} \mathrm{O}$ ratios were measured on a gas $\square$ mass 
spectrometer MAT253. Hydrogen isotope was tested by pyrolysis method which had the precision result of $1 \% o$. Oxygen isotope was tested by water equilibrium method which had the precision result of $0.1 \%$ o. GB method of determination of total phosphorus method-- Ammonium molybdate spectrophotometric method ( GB 11893-89 ) was used. This standard was suitable for surface water, wastewater and industrial water.

\section{Results and Discussion}

\section{Transformation law of hydrogen and oxygen isotopes}

In the experiment, soil samples were collected two times by the sampler of soil solution (Rhizon-SMS). According to the order of outflowing water, we collected 7 samples of gravity water. The hydrogen and oxygen isotopic values of soil water collected in situ were shown in table 1 . The hydrogen and oxygen isotope values of gravity flow samples and the initial water were in table 2.

Table 1 Hydrogen and oxygen isotope values of the samples collected in situ

\begin{tabular}{|c|c|c|c|c|c|}
\hline Name & $\delta \mathrm{D}(\% \circ)$ & $\delta^{18} \mathrm{O}(\% \circ)$ & Name & $\delta \mathrm{D}(\% \circ)$ & $\delta^{18} \mathrm{O}(\% \circ)$ \\
\hline Situ sampling 1a & -47.0 & -6.84 & Situ sampling 2a & -41.2 & -5.43 \\
\hline Situ sampling 1b & -48.0 & -6.98 & Situ sampling 2b & -42.0 & -5.59 \\
\hline Situ sampling 1c & -44.5 & -5.74 & Situ sampling 2c & -43.7 & -5.79 \\
\hline Situ sampling 1d & -24.0 & -3.18 & Situ sampling 2d & -44.2 & -5.88 \\
\hline
\end{tabular}

Table 2 Hydrogen and oxygen isotope values of gravity flow samples and the initial water

\begin{tabular}{|c|c|c|c|c|c|}
\hline Name & $\delta \mathrm{D}(\%)$ & $\delta^{18} \mathrm{O}(\% \circ)$ & Name & $\delta \mathrm{D}(\% \circ)$ & $\delta^{18} \mathrm{O}(\%)$ \\
\hline Gravity flow -1 & -32.1 & -4.71 & Gravity flow -5 & -37.9 & -5.06 \\
\hline Gravity flow -2 & -36.0 & -5.59 & Gravity flow -6 & -42.7 & -5.79 \\
\hline Gravity flow -3 & -38.7 & -5.49 & Gravity flow -7 & -44.5 & -6.59 \\
\hline Gravity flow -4 & -40.2 & -5.89 & Initial water & -48.7 & -7.21 \\
\hline
\end{tabular}

The relationship between hydrogen and oxygen isotope values was shown in fig 3 .

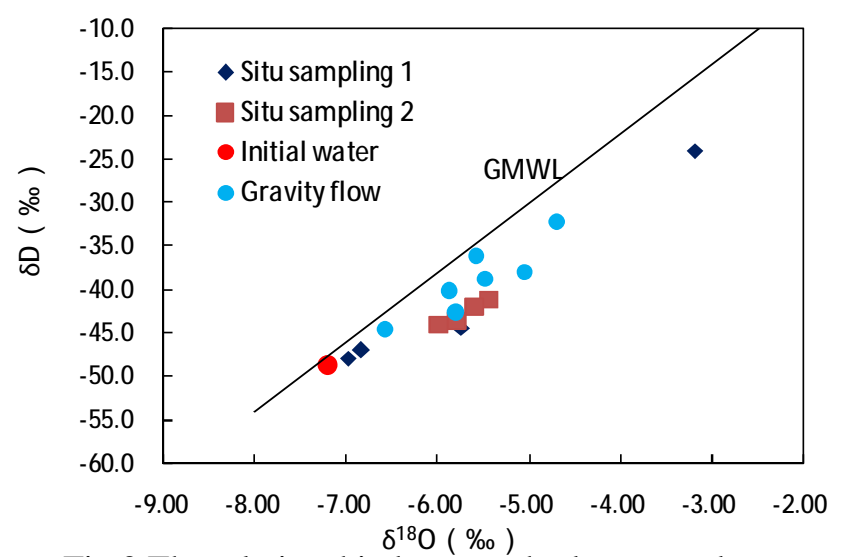

Fig 3 The relationship between hydrogen and oxygen isotope values

Combining table 1 with table 2, in fig 3 the values of hydrogen and oxygen isotopes of the sampling point of $1 \mathrm{a}$ and $1 \mathrm{~b}$ were very closed according to the order from top to the bottom. The isotopic values deviated $1 \%$ and $0.3 \%$ o from the initial water. The hydrogen and oxygen isotopes values of the sampling point $1 \mathrm{c}$ and $1 \mathrm{~d}$ deviate from initial water constantly. The hydrogen and oxygen isotopes values of the situ sampling $1 \mathrm{~d}$ sample were $-24.0 \%$ and $-3.18 \%$.The sampling depth of the situ sampling 1d sample was $100 \mathrm{~cm}$, which had the longest way of infiltration. Air-dried soil particles only contained soil hygroscopic water. When the rainfall permeate above the soil column, soil particle can still adsorb certain water and form pellicularzone, in which isotope 
fractionation of the infiltration water was caused ${ }^{[9,20]}$. Also we can find that soil particles adsorb light water preferentially, which resulted that the hydrogen and oxygen isotopes values of the flowing water in the soil were modified. Combined with the values of hydrogen and oxygen isotopes of gravity water, we can see that the first outflow sample had the most modified isotope values. Along with the gravity water increasing, the hydrogen and oxygen isotopic values of samples were gradually close to the rainfall. The hydrogen and oxygen isotopic values of the last outflow sample were sill modifying than initial values, which was caused by the loss of the collected outflow. The hydrogen and oxygen isotopic values of the four soil water samples collected in the second time were closed to each other. It showed that after flowing out a certain sum of gravity water, the water in soil column distributed uniformly.

\section{Transformation law of phosphate content}

After phosphorus in wastewater infiltrated into soil profile, we obtained that phosphate content vary with the depth of the sampling point in the first collecting time of soil water in situ. The relationship between phosphate content and depth were shown in picture 4 . We can conclude that phosphate content of soil water was decreasing along with the depth of sampling increasing, and they were all less than the initial phosphate content. Along with the depth of sampling increasing, the process of soil water purifying was longer and the purification effect was better. Phosphate can be wiped off by the method of chemisorption, physical adsorption, chemical reaction and precipitation so on. Comparing the effect of soil purifying phosphate in the condition of acid with the condition of alkaline, soil particle had more better effect of purifying phosphate in the condition of acid.
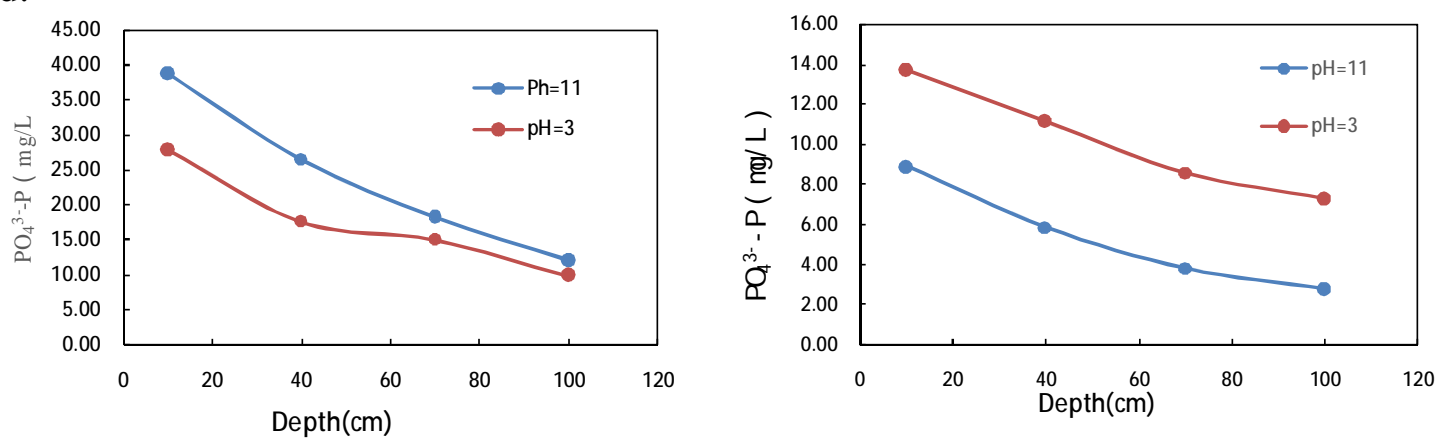

Fig 4 The first sample in situ, the relationship between phosphate content and depth

Fig 5 The second sample in situ, the relationship between phosphate content and depth

After soil column leaching by rainfall and gravity water flowing out, we collected the samples of soil water in situ in different horizons of the soil column. The relationship between phosphate content and depth was shown in the picture 5. From the picture 5, it was concluded that the phosphate content of soil content were obviously decreased after rainfall leaching. The minimum phosphate content was $2.8 \mathrm{mg} / \mathrm{L}$. Along with the depth increasing of the column, phosphate content was decreasing successively. It can illustrate that phosphate which was absorbed by soil was easily taken by water. From picture 5, we can also conclude that phosphate in the soil column of alkaline was easily taken out after leached by rainfall. The soil in the condition of acid had better effect of purifying phosphorus in wastewater, which was difficult to leach using rainfall relatively.

\section{Conclusion}

The rainfall and sewage infiltration process were simulated through the soil column experiment. Through the analysis of hydrogen-oxygen isotope values and phosphate content, the conclusion is 
that in the rainfall infiltration process of dry soil, the light water molecules are first adsorbed by soil particles, the flow water in soil column had positive values. The first gravity flow water sample had the most positive isotope values. With an increased amount of gravity flow water, the oxygen and hydrogen isotopes were closed to the initial water. The phosphate content of soil water showed that soil particles had the purification effect to the phosphate in wastewater, and the purification effect under acidic conditions was better than alkaline conditions. Under alkaline conditions, the phosphate was more easily rinsed out.

\section{Acknowledgements}

This work was supported by the university research fund of Nanjing Institute of Technology (Grant No. YKJ201327).

\section{References}

[1] Yang Hongbin. Fractionation mechanism of hydrogen and oxygen stable isotope in unsaturated zone of semi-arid area. Xi'an University of Science and Technology,2014.

[2] Liu Jun, Wei Wen, Zhang Lin, etal.. Application on Isotopes D and 180 of Soil Water in Water Movement of Unsaturated Zone. Site Investigation Science and Technology, 2012(5):39-43.

[3] Adomako D, Maloszewski P, Stumpp C, et al. Estimating groundwater recharge from water isotope $(2 \mathrm{H}, 18 \mathrm{O})$ depth profiles in the Densu River basin, Ghana[J]. Hydrological Sciences Journal,2010, 55( 8) : 1405- 1416.

[4] Brodersen C, Pohl S, Lindenlaub $M$, et al. Influence of vegetation structure on isotope content of through fall and soil water[J]. Hydrol.Processes, 2000(14): 1439-1448.

[5] Wang Shiqin, Song Xianfang, Xiao Guoqiang, etal. Appliance of oxygen and hydrogen isotope in the process of precipitation infiltration in the shallow groundwater areas of North China Plain. Advances in water science, 2009,20(4): 495-501.

[6] Xu Xuexuan, Zhang Beiying, Tian Junliang. Experimental study on the precipitation-soil watergroundwater transformation in loess hilly region. Advances in water science, 2010,21(1):16-22.

[7] Yuan Cuiping, Zhang Xinping, Lei Tingwu, etal. Effects of mulching sand and gravel size on soil moisture evaporation. TRANSACTIONS OF THE CHINESE SOCIETY OF AGRICULTURAL ENGINEERING, 2008,24 (7): 25-28.

[8] Song Riquan, Chu Guixin, Ye Jun, etal. Effects of surface soil mixed with sand on water infiltration and evaporation in laboratory. Transactions of the Chinese Society of Agricultural Engineering, 2010 , 26(Suppl.1) : 109-114

[9] Sun Xiaoxu, Chen Jiansheng, Shi Gongxun, etal. Hydrogen and oxygen isotopic variations of different water bodies in evaporation and rainfall infiltration processes. Transactions of the Chinese Society of Agricultural Engineering, 2012,28 ( 4 ): 100-105.

[10] Grifoll J .,Cohen Y . Contaminant migration in the unsaturated soil zone: the effect of rainfall and evapotranspiration [ J ] . Journal of Contaminant Hydrology,1996,23:185-211 . 
[11] Marshall J. D., Shimada B.W., Jaffe P. R. Effect of temporal variability in infiltration on contaminant transport in the unsaturated zone [ J ] .Journal of Contaminant Hydrology,2000,46: 151-161 .

[12] Li Hong, Li Xingang, Huang Guoqiang, etal. Numerical simulation of contaminant transport in vadose zone during rainfall and evaporation. CHEMICAL ENGINEERING, 2007,35( 9) : $51-54$

[13] Zuo Zibo, Zhang Lulu, Wang Jianhua. Numerical Simulation of Contaminants Transport in Unsaturated Soils under Rainfall. Chinese Journal of Underground Space and Engineering,2011, 07(z1):1347-1352.

[14] Lin Fei, Song Dejun, Tao Yuezan, etal. Trend analysis of chloride migration in saturated silty sand under different rainfall. Water Resources and Power, 2014,32(9):51-54.

[15] Wang Chao. Experimental Study of Nitrogen Transportand Transformation in Soils. Advances in Water Science, 1997,8(2):176-182.

[16] Wang Yanan, Wang Hongqi, Shu Yan. Simulated study on transferring and transforming of phosphorus in soil leached by waste water. Acta Scientiae Circumstantiae,2001, 21(6):737-741.

[17] Ji Xueyan, Liu Xiaoyan, Li Xingwei, etal. Soil columns' experiments by layers of the migration of petroleum hydrocarbons contaminants in soils.Energy Environmental Protection, 2005,19(1): 43-45.

[18] Xiao Chunyan, Tai Chao, Zhao Tongqian, etal. Transport of organochlorine pesticides between the interface of soil and water by rainfall simulation method. Environmental Chemistry, 2012, 31(12):1953-1959.

[19] Aragufis L, Rozanski K, Gonfiantini R, et al. Isotope effects accompanying vacuum extraction of soil water for stable isotope analyses[J]. Journal of Hydrology, 1995, 168(1/4):159 - 171. 